\title{
Study on Reform of Classroom Teaching Quality Assessment Method for College Teachers
}

\author{
Biao Zhu \\ Yanbian University, Yanji Jilin, 133002, China
}

Keywords: College teachers, Classroom teaching quality evaluation, Status, Measures

\begin{abstract}
Currently, college classroom teaching quality evaluation has various problems, such as the complexity of evaluation object, ambiguity of evaluation purpose, incompleteness of evaluation method and irrationality of evaluation index. This paper analyzes classroom teaching quality evaluation system in colleges and universities and establishes a scientific and comprehensive classroom teaching quality evaluation system to improve school teaching quality in terms of reasonable course setting, reasonable arrangement of participants of evaluation, reasonable establishment of evaluation index, reasonable analysis of evaluation result and effective utilization of feedback result.
\end{abstract}

\section{Status of classroom teaching quality assessment method for college teachers}

Classroom teaching of college teachers plays an important role in college talent training. The quality of classroom teaching is the most direct factor of talent training. In addition, classroom teaching quality evaluation system of teachers is an important content of college education evaluation, which has close connection with college teaching management, as well as an important means and link for the implementation of educational management. The implementation of classroom teaching quality evaluation can effectively help teachers sum up experience and improve teaching methods and contents as well as teaching level. Meanwhile, the establishment of classroom teaching quality evaluation system can help schools establish a standardized and scientific teaching management system. Therefore, many domestic and foreign colleges and universities have taken certain measures for the establishment of classroom teaching evaluation system and made attempts in some relevant aspects.

\section{Status of classroom teaching quality assessment method for college teachers in foreign countries}

As is known to all, foreign educational level is more advanced than domestic one. Therefore, the establishment and implementation of teaching quality evaluation system in foreign countries is different from that in China. In foreign colleges and universities, teaching quality is mostly evaluated in three aspects, including students' mastery degree of knowledge, students' practical ability in social practice and attraction degree of teachers' teaching to students. Moreover, the following characteristics are manifested in its research and practice of teaching quality evaluation: first, attach importance to discussion and communication between students and teachers or among students; second, emphasize the importance of cooperation among students in classroom teaching process; finally, emphasize the spirit of exploration and innovation and arouse students' interest in terms of the way of educating students in study. Therefore, in terms of teaching quality evaluation system, foreign countries not only require teachers to impart knowledge to students in the teaching process, but also emphasize the importance of training students’ practical abilities through classroom teaching.

\section{Status of classroom teaching quality assessment method for college teachers in China}

Since the reform and opening up, classroom teaching quality evaluation system for college teachers in China has been constantly improved and mainly experienced paper print media evaluation, electronic reading evaluation and current evaluation with network lesson evaluation system. Relevant theoretical studies on classroom teaching are mainly studies about the training of students' initiative and innovation and school teaching system. In terms of school classroom teaching quality evaluation, teachers' classroom teaching quality, method and content are evaluated with the method of 
combining students' anonymous evaluation, lesson evaluation of teaching supervisor and informal discussion of student representatives. Such method of combining students' evaluation for teachers and peers' evaluation shows achievements of teachers' classroom teaching comprehensively and objectively. With the constant improvement of quality evaluation system, Chinese college educational management system has been constantly improved, thus stimulating teachers to constantly improve teaching method, content and attitude and improve teaching quality level.

In terms of research status, evaluation media and technologies have been constantly improved and innovated after classroom teaching evaluation system of college teachers experienced continuous improvement. Even though evaluation system is constantly updated with advanced network information technology, the basic evaluation mode has not changed. Evaluation is still conducted through comparison with preset indicators and the focus of attention is also teachers' teaching content, method, attitude and effect. The evaluation of teachers' teaching behavior, process and emotion is lacking. Therefore, the current teaching quality evaluation system still has deficiencies. Even though studies on relevant problems are involved, differences of teaching characteristics of different majors are not considered. Teaching evaluation system cannot meet current teachers' classroom evaluation demands.

\section{Problems existing in current classroom teaching quality evaluation method of colleges and universities}

It is difficult to realize scientificalness and comprehensiveness of teaching evaluation system.

The profession of teacher is a special industry. Teachers' behaviors need to have certain constraints. From individual perspective, teachers are a sensitive group. Classroom teaching evaluation result of colleges and universities not only influences the value of teachers, but also concerns whether their expected social value can be recognized. Therefore, the establishment and implementation of classroom teaching quality evaluation in colleges and universities is a relatively sensitive issue. This makes requests for the objectivity and scientificalness of college teaching evaluation. Otherwise, the evaluation of teaching quality cannot arouse the enthusiasm of teachers and will produce negative influence in psychology and influence teaching due to the irrationality of evaluation result. Therefore, classroom teaching quality evaluation of college teachers should be as complete as possible with respect to evaluation index setting, establishment of evaluation standard, level of estimators participating in evaluation and requirements for them. Only in this way can the reliability of evaluation result be improved.

\section{It is difficult to realize individual difference of evaluation objects}

The same evaluation standard is used for classroom teaching quality evaluation of teachers in colleges and universities so as to determine teachers' teaching level. However, the current evaluation system has serious deficiencies: first, evaluation subject and object; teachers in different majors have different teaching content, way, method, purpose, process and attitude. For example, teachers of specialized courses focus on teaching students to understand professional theoretical basis and meanwhile paying attention to the teaching method combining practice. For pen courses, teachers only need to popularize relevant knowledge and allow students to understand and absorb certain knowledge in the listening process and then use it. Teachers of different specialized courses have certain differences in teaching method. The result of the same evaluation index is unreasonable for different teachers. In addition, in terms of evaluation index, too complicated indicators cannot highlight the typical or differentiate the primary and the secondary, thus causing low score of excellent teachers in evaluation result and little difference of score of lagging teachers and resulting in unreasonable phenomenon.

Therefore, if reasonable evaluation indicators cannot be established according to differences of evaluation objects, the evaluation result will become unreasonable, which will not improve the work of teachers and instead will produce negative influence on them and even reduce the work efficiency of some teachers. 


\section{Indicator system of classroom teaching quality evaluation lacks scientificalness}

The evaluation result of classroom teaching quality evaluation system for college teachers has certain limitation and abstraction and lacks scientificalness. First, in terms of personnel participating in evaluation, teachers' classroom teaching quality in colleges and universities is mostly evaluated by students and other teachers except the one to be evaluated. Teachers are evaluated with individual subjective preference and the result will have certain deviation. Second, the evaluation of teachers by students lacks certain reference object. For example, students do not have reference data such as teaching schedule, teaching program and other aspects for the indicator "knowledge update" and cannot make a reasonable evaluation according to practical situation. Finally, differences are not manifested in indicator setting for different grades. That is to say, evaluation indicators for teachers in grade one and grade four are the same in the evaluation form of students during teachers' classroom teaching quality evaluation. Students in different grades have differences in the recognition of teachers. Teaching methods and contents of teachers are also different. Such generalized evaluation indicator system does not differentiate. The evaluation result has certain limitation and lacks scientificalness.

\section{Basic measures for establishing scientific college classroom teaching quality evaluation system}

\section{Study on implementation of classroom teaching method and course system}

Classroom teaching quality of teachers is related to teaching level, method and ability of teachers and course setting. College course setting should consider resource optimization theory and objective management theory, train students' practical abilities, combine course setting and enterprises and achieve organic combination of theories learnt and practical abilities. In addition, when deepening the reform of teaching quality evaluation system, schools should comprehensively carry out education policies of the Party, implement quality-oriented education for students, organically combine knowledge and cultural education and scientific theory education and integrate them into the training of college talents. It is required to constantly improve course setting and arrangement, allow teachers to participate in teaching research of course reform, improve their teaching ability and team building, provide students with high-quality teaching and train all-round high-quality talents for the country.

\section{Study on classroom teaching quality evaluation system}

Colleges and universities can first consider increasing the right of teachers to participate in the setting of indicator system in terms of the establishment of quality evaluation indicator system in the process of reforming teachers' classroom teaching quality evaluation method. Teachers are front-line executors of classroom education, who have the most direct feelings for classroom education. Therefore, they have authoritative right to speak for the establishment of evaluation standard. Second, it is necessary to expand the scope of evaluation participants in the previous classroom teaching evaluation system, divide the scope into five parts - students, experts, colleagues, teachers and enterprise experts related to students' internship, conduct investigations in multiple forms, set up relevant indicators in multiple aspects such as the degree of satisfaction of students for teachers' teaching, teachers' academic level and practical abilities, and establish a comprehensive teaching quality evaluation system. Moreover, colleges should determine the specific weight of each aspect and form a scientific brand new indicator evaluation system after constant modification and practice. The establishment of such indicators aims at improving teachers' teaching quality, impelling them to make constant improvements in multiple aspects according to practical demands and improving their teaching level and ability.

Establishment of reasonable evaluation indicator mechanism of classroom teaching quality

Currently, the establishment of evaluation indicators of teachers' classroom teaching quality has certain limitation. On the whole, indicators selected are not comprehensive. The complexity of college teaching courses makes classroom teaching evaluation more difficult. Therefore, the selection of indicators of college classroom teaching quality evaluation should be considered comprehensively. Besides the establishment of evaluation indicators for such items as teachers' teaching method, content, ability, attitude and effect, it is also required to consider the evaluation of experts for 
students' practical ability, teachers' self-evaluation and other reasons influencing teachers' teaching quality evaluation, evaluate the teaching effect of teachers comprehensively and reasonably and establish a scientific and reasonable evaluation system for college teachers' classroom teaching quality. Only with the establishment of reasonable classroom teaching quality evaluation indicators can we have rules to follow in the evaluation process, avoid negative influence of subjective factors in classroom teaching quality evaluation process and obtain more real, effective, objective and fair results of classroom teaching quality evaluation.

\section{Reinforcement of feedback and utilization of classroom teaching quality evaluation result}

The establishment of classroom teaching quality evaluation system aims at allowing schools and teachers to analyze reasons for existing problems and improvability comprehensively and systematically by analyzing problems fed back through the feedback result of teaching so as to improve the teaching level and quality of schools and teachers. Evaluation result should be analyzed and summarized comprehensively. As influencing factors of the result involve multiple aspects, besides teachers and students, the difference of course will also influence students' evaluation result. Therefore, the influence of different estimators and courses on the result should be considered during effective analysis on evaluation result. Meanwhile, it is required to analyze the specific reason, whether individual or overall reason, so as to judge out the problem of teachers' teaching or course setting and teaching management so that teachers and schools can understand their problems accurately, make constant improvements and improve the teaching quality of schools. If the teaching quality of teachers is judged only according to the evaluation result, it is unfair and will produce certain influence on teachers' instructional psychology. Therefore, objective treating and analyzing teaching quality evaluation result cannot be neglected.

\section{Conclusion}

This paper puts forward serious deficiencies of the current teaching quality evaluation system through analysis on the status of classroom teaching quality evaluation system in domestic and foreign colleges and universities. For specific problems existing in college classroom teaching quality evaluation system, this paper proposes to establish a comprehensive and scientific teaching quality evaluation system, divide subjects participating in evaluation, consider factors that might influence the result of indicators and comprehensively analyze possible reasons for the evaluation result so that teachers and schools can find out their problems, make improvements in time and improve their teaching level and quality.

\section{References}

[1] Gao Qiang, Li Xiulian, Zhang Huiru. Study on College Classroom Teaching Quality Evaluation. Journal of Hubei University of Economics (Philosophy and Social Science Edition), 2010(4).

[2] Qu Xiaohui, Bo Lili. Discussions on Problems of College Classroom Teaching Evaluation and Countermeasures. Continuing Education Research, 2012(9).

[3] Cui Xiaohang, Jiang Junhe. Study on College Teachers’ Teaching Quality Evaluation Method. Journal of Shenyang College of Education, 2003(3).

[4] Zhou Hailin. Analysis on Problems of College Teachers' Classroom Teaching Quality Evaluation and Countermeasures. Education Exploration, 2010(4).

[5] Lu Shanhua, Li Zhuliang, Wang Jianfei. Discussions on College Classroom Teaching Quality Evaluation Method and Its Feedback Mechanism. Journal of Anhui Technical Teachers' College, 2013(2). 